\title{
Clinico-pathological profile of primary lung cancer in a tertiary care center in South India
}

\author{
Rajkrishnan Soman ${ }^{1}$, Vishnukanth Govindaraj ${ }^{2, *}$, Vinodkumar Saka ${ }^{3}$, Bhavana Badhe $^{4}$, Biswajit Dubashi ${ }^{5}$ \\ ${ }^{1}$ Junior Resident, ${ }^{2}$ Asociate Professor, ${ }^{3}$ Senior Professor and HOD, ${ }^{1-3}$ Dept. of Pulmonary Medicine, ${ }^{4}$ Senior Professor, Dept. of \\ Pathology, ${ }^{5}$ Additional Professor, Dept. of Medical Oncology, Jawaharlal Institute of Postgraduate Medical Education and \\ Research, Puducherry, India
}

*Corresponding Author:

Email: vishnu1429@yahoo.com

\begin{abstract}
Background: Lung is one of the commonest site for malignant neoplasms, both primary and metastatic. Primary lung malignancies are presently heading the list of common cancers worldwide and accounts for more death than any other cancer. In lung cancer, diagnosis of histological type is of great significance to determine the prognosis and for planning the treatment. Radiology and imaging plays an integral part in diagnosis, management, staging and follow-up of lung cancer patients. Moreover, radiology can give vital clues towards histological diagnosis of the malignancy. Our study aims to analyse the clinical, radiological and histological patterns occurring in patients with primary lung cancer.

Materials and Methods: A total of 116 patients with clinical and radiological features suggestive of primary lung cancer were enrolled. Diagnosis of lung cancer was established histopathologically. Clinico-pathological profile and histopathological analysis was done individually for all patients.

Results: Our study included a total of 116 cases with 84 males (72\%) and 32 (28\%) female patients with a median age of 60 years (range 19-90 years). The most common histological type of lung cancer was adenocarcinoma, in 79(69.82\%) of patients followed by squamous cell carcinoma in 22 patients (18.96\%). Adenocarcinoma was the most common type among both males and females. Also adenocarcinoma was the commonest histological pattern among non-smokers. The most common clinical presentation was cough with expectoration. Radiologically most common feature was mass lesion (86.2\%). Seventy four patients $(63.78 \%)$ with non-small cell lung cancer had metastatic disease, the most common being malignant pleural effusion. Six out of seven patients of small cell cancer had extensive stage.

Conclusions: Adenocarcinoma is the commonest histological pattern of lung cancer even in smokers. Lung cancer is not necessarily a disease of old age. Majority of the patients still present in advanced stages. A good screening method for lung cancer is the need of the hour.
\end{abstract}

Keywords: Adenocarcinoma; Primary lung cancer; Pathological profile.

\section{Introduction}

Primary lung malignancies head the list of commonest cancers in the world and accounts for more deaths than any other cancer[1]. Primary lung cancers are mostly found among smokers. But the number of non-smokers with lung cancer is also showing alarming increase in the recent years. This could be attributed to the increase in other risk factors like passive smoking, environmental tobacco smoke, asbestos, radon and other occupational and environmental exposures and genetic factors[2-4].

Primary lung cancers are divided into two main type, small cell carcinoma (SCLC) and non-small cell lung carcinoma (NSCLC). NSCLC accounts for most of the primary lung cancers and has 3 major typesAdenocarcinoma, Squamous cell carcinoma and large cell carcinoma. Small cell carcinoma is lesser in incidence compared to NSCLC, but shows distinct clinical and pathological features.

The clinical manifestations of lung cancer can be brought together under four categories, those related to primary lesions; those related to intrathoracic spread, those related to distant metastasis and those related to paraneoplastic syndromes.
Radiological imaging plays an integral part in diagnosis, management, staging and follow up of lung cancer patients. Computed tomography scan helps in more accurate localisations and anatomical details to plan for further interventions and stage classification. Also, radiological appearances give vital clues towards histological diagnosis of the malignancy.

\section{Aims and Objectives}

This study aims to analyse the clinical and radiological features associated with different histological primary lung cancers.

\section{Materials and Methods}

The present study was conducted in department of pulmonary medicine, Jawaharlal Institute of Postgraduate Medical Education and Research, a tertiary care level hospital in South India in collaboration with departments of medical oncology, pathology and radio-diagnosis from July 2015 to June 2017. A total of 140 diagnosed cases of primary lung cancer diagnosed radiologically and histopathologically were enrolled for the study. The study was conducted after obtaining ethical committee approval from the institute. 
Out of the 140 patients, 18 patients lost follow up and metastatic evaluation could not be completed. 6 patients expired before evaluation was complete. So excluding these cases, 116 cases were included in the study. Once diagnosis of primary lung cancer was established, metastatic work up was done for all 116 cases. CECT-Thorax with abdomen, 2D-Echocardiograph, bone-scan were done for metastatic evaluation. CT -Brain was taken in all cases with small cell histology and suspected cases with other histology's. Following complete evaluation, the patients were staged in accordance with IASLC-7 staging. Based on the study objective, clinic-radiological and pathological profile of proven primary lung cancer was analysed.

\section{Results}

A total of 116 patients comprising of 84 males and 32 females were included in the study. The most common age group of presentation was between 50-70 years (mean-60.04 years). [Table 1]

Table 1: Age distribution of study subjects with primary lung cancer

\begin{tabular}{|c|c|}
\hline Age group & Number \\
\hline $10-20$ & 1 \\
\hline $20-30$ & 2 \\
\hline $30-40$ & 5 \\
\hline $40-50$ & 18 \\
\hline $50-60$ & 37 \\
\hline $60-70$ & 36 \\
\hline $70-80$ & 14 \\
\hline $80-90$ & 3 \\
\hline & $\mathrm{N}=116$ \\
\hline
\end{tabular}

The male to female ratio in our study was $2.68: 1$. Of the 116 patients 65 person $(56.34 \%)$ had history of smoking comprising of 63 male patients and 2 female patients. Among non-smokers 21 were males and 30 were females. [Table 2]

Table 2: Distribution of smokers and Nonsmokers among study subjects with primary lung cancer

\begin{tabular}{|l|c|c|}
\hline Smoking status & Number & Percentage \\
\hline Smokers & 65 & $56.34 \%$ \\
\hline Nonsmokers & 51 & $43.66 \%$ \\
\hline Total & 116 & 100 \\
\hline
\end{tabular}

Most of the patients had multiple presenting complaints. The most common clinical presentation was cough with expectoration. Cough was present in 107 patients and 75 of these patients had associated expectoration. The second most common presentation was shortness of breath seen in $65 \%$ of the patients. 26 patients $(22.4 \%)$ had hemoptysis. Hoarseness of voice was seen in 29 patients. [Table 3]
Table 3: Frequency of individual symptoms among study subjects with primary lung cancer

\begin{tabular}{|l|c|c|}
\hline \multicolumn{1}{|c|}{ Symptom } & $\begin{array}{c}\text { Number of } \\
\text { patients }\end{array}$ & Percentage \\
\hline Cough & 107 & 92.24 \\
\hline Expectoration & 75 & 64.65 \\
\hline Dyspnoea & 75 & 64.65 \\
\hline Loss of Appetite & 74 & 63.79 \\
\hline Loss of Weight & 68 & 58.68 \\
\hline Chestpain & 27 & 23.27 \\
\hline Hemoptysis & 26 & 22.27 \\
\hline Fever & 23 & 19.82 \\
\hline $\begin{array}{l}\text { Hoarseness of } \\
\text { voice }\end{array}$ & 11 & 9.48 \\
\hline Backpain & 6 & 5.17 \\
\hline Dysphagia & 5 & 4.31 \\
\hline
\end{tabular}

On clinical examination- Clubbing was seen in 56 cases $(48.27 \%)$.Palpable lymphadenopathy was present in 33 cases $(28.44 \%)$. Features of SVC syndrome was seen in 11 patients $(9.48 \%)$. There were also 11 cases with Horner's syndrome and 9 cases $(7.75 \%)$ with Pancoast syndrome. [Table 4]

Table 4: Profile of clinical signs in study subjects with primary lung cancer

\begin{tabular}{|l|c|c|}
\hline \multicolumn{1}{|c|}{ Clinical sign } & Number & Percentage \\
\hline Clubbing & 56 & 48.27 \\
\hline Palpable lymph node & 33 & 28.44 \\
\hline Pallor & 27 & 23.27 \\
\hline $\begin{array}{l}\text { Superior vena cava } \\
\text { obstruction(SVC)- }\end{array}$ & 11 & 9.48 \\
\hline Horner's syndrome & 11 & 9.48 \\
\hline Pancoast syndrome & 9 & $7.75 \%$ \\
\hline
\end{tabular}

Radiologically, most of the patients in our study had multiple findings. Most common chest radiographic feature was mass lesion. Isolated mass lesion on the right side was present in 18 cases. Mass with lung collapse was found in 19 patients, while mass with pleural effusion was present in 20 patients. The other radiological appearances were collapse of right lung in $54(46.655 \%)$ patients, pleural effusion in $45(38.77 \%)$ patients and consolidation in 13 patients $(11.20 \%) .3$ patients presented with cavitatory lung lesion. [Table 5]

Table 5: Frequency of individual findings on chestxray among study subjects with primary lung cancer

\begin{tabular}{|l|c|c|}
\hline \multicolumn{1}{|c|}{ Finding } & Number & Percentage \\
\hline Lung mass & 100 & $86.20 \%$ \\
\hline Collapse of lung & 54 & $46.55 \%$ \\
\hline Pleural effusion & 45 & $38.77 \%$ \\
\hline Lung Consolidation & 13 & $11.20 \%$ \\
\hline $\begin{array}{l}\text { Solitary pulmonary } \\
\text { nodule }\end{array}$ & 3 & $2.58 \%$ \\
\hline Lung cavity & 3 & $2.58 \%$ \\
\hline
\end{tabular}


CT thorax was done in all 116 patients. The most common CT feature was mass lesion in the right upper lobe which was detected in $100(86.20 \%)$. Solitary pulmonary nodule was seen in $3(3.3 \%)$ cases. Mediastinal adenopathy was seen in 37(31.89\%). Local infiltration of the mass to vessels (SVC, pulmonary artery, aorta) was present in $18(15.51 \%)$ cases. Infiltration to chest wall was detected in $12(10.34 \%)$ cases while metastasis to opposite lung was found in 24 cases. [Table 6]

Table 6: Distribution of individual findings on CECT Thorax in study subjects with primary lung cancer

\begin{tabular}{|l|c|c|}
\hline \multicolumn{1}{|c|}{ Findings } & Number & Percentage \\
\hline Lung Mass & 100 & 86.20 \\
\hline Lung Collapse & 54 & 46.55 \\
\hline
\end{tabular}

\begin{tabular}{|l|c|c|}
\hline Pleural effusion & 45 & 38.77 \\
\hline Mediastinal adenopathy & 37 & 31.89 \\
\hline $\begin{array}{l}\text { Blood- vessel } \\
\text { involvement }\end{array}$ & 18 & 15.51 \\
\hline Consolidation & 13 & 11.20 \\
\hline Chest-wall involvement & 12 & 10.34 \\
\hline $\begin{array}{l}\text { Solitary Pulmonary } \\
\text { Nodule (SPN) }\end{array}$ & 3 & 2.58 \\
\hline Lung cavity & 3 & 2.58 \\
\hline
\end{tabular}

Out of the 116 cases, the most common histological type of lung cancer was adeno carcinoma which was seen in 79(69.82\%) of patients. The second common type was squamous cell carcinoma which was seen in 22 patients $(18.96 \%)$. There were 7 cases of small cell carcinoma, 5 carcinoids and 1 case of inflammatory myofibroblastic tumour and 2 cases of adenosquamous carcinomas. [Table 8]

Table 7: Frequency of Individual site metastasis among study subjects with primary lung cancer

\begin{tabular}{|l|c|c|c|}
\hline \multicolumn{1}{|c|}{ Metastasis } & Number & $\begin{array}{c}\text { Percent } \\
\text { of total }\end{array}$ & $\begin{array}{c}\text { Percent of } \\
\text { metastasis }\end{array}$ \\
\hline Pleural effusion & 32 & 27.58 & 43.24 \\
\hline contralateral lung & 24 & 20.68 & 32.43 \\
\hline Lymph node & 18 & 15.51 & 24.32 \\
\hline Pericardial effusion & 17 & 14.65 & 22.97 \\
\hline Bone & 14 & 12.06 & 18.91 \\
\hline Liver & 9 & 7.75 & 12.16 \\
\hline Adrenal & 9 & 7.75 & 12.16 \\
\hline Brain & 9 & 7.75 & 12.16 \\
\hline
\end{tabular}

Table 8: Histopathological profile of study subjects with primary lung cancer

\begin{tabular}{|l|c|c|}
\hline \multicolumn{1}{|c|}{ Histopathological Type } & Number & Percentage \\
\hline Adenocarcinoma & 79 & 68.16 \\
\hline Squamous cell carcinoma & 22 & 18 \\
\hline Small cell carcinoma & 7 & 6.33 \\
\hline Carcinoid tumors & 5 & 4.31 \\
\hline $\begin{array}{l}\text { Inflammatory myofibroblastic } \\
\text { tumour }\end{array}$ & 1 & 0.95 \\
\hline Adenosquamous carcinoma & 2 & 1.71 \\
\hline
\end{tabular}

There were 74 cases $(63.78 \%)$ with metastatic disease. 51 patients had multiple metastasis. 32 patients (27.58\%) had malignant pleural effusion, which was the most common metastasis, followed by contralateral lung metastasis in $24(20.68 \%)$ cases. There were $18(15.51 \%)$ cases with lymph node metastasis, 17 $(14.65 \%)$ with metastatic pericardial effusion, $14(12.06 \%)$ with bone metastasis, $9(7.75 \%)$ each with liver, adrenal and brain metastasis. [Table 7]

Adenocarcinoma was the most common type among both males and females. Adenocarcinoma accounted for 79 cases comprising of 50 males and 29 females. Also adenocarcinoma was the commonest histological pattern among 41 non- smokers.

All the diagnosed cases of primary lung cancer were staged according to the International Society for
Study on Lung Cancer (IASLC -7) Staging system[13]. Among the 103 patients of non-small cell carcinoma, 68 patients were in stage-IV, 18 patients had stage-III, 11 patients had stage-II and 6 patients had stage-I. Among small cell lung cancer, out of 7 patients, 6 had extensive stage and one patient had limited stage disease. [Table 9]

Table 9: Stage distribution of study subjects with primary lung cancer(IASLC-7)

\begin{tabular}{|c|c|}
\hline Stage & Number of patients \\
\hline I & 6 \\
\hline II & 11 \\
\hline III & 18 \\
\hline IV & 68 \\
\hline
\end{tabular}




\section{Discussion}

The mean age of lung cancer patients in our study was 60.04 years establishing the fact that lung cancer is a disease of old age. This is comparable to the study done by Kumar et al., in North India and Dhandapani et al., in South India, both of which showed a mean age group close to 60 years[5,6].

However our study involved a wide age group with age ranging from 19 years to 90 years. To the best of our knowledge only one similar study had such a wide age range[5]. The male to female ratio in our study was 2.68:1 indicating the increasing incidence of lung cancer among females. The smoker to non-smoker ratio of lung cancer in our study (ratio 1.27:1) is higher than other studies[28,29,32]. This implies that lung cancer is showing a rising trend among the non-smoker population.

Most of the study subjects presented with multiple symptoms. Cough was the most common symptom and was present in $92.24 \%$ patients similar to previous studies [5-12]. The incidence of hemoptysis $(22.40 \%)$ is also similar to other studies.[5,7,9] Hoarseness of voice as a presenting symptom was seen in $25 \%$ of our study population identical to study by Gupta et al.[9].

Clubbing was noted in $48.27 \%$ of our patients which is significantly than $30 \%$ noted in other studies[5,9]. The incidence of SVC syndrome $(9.48 \%)$ and Horner's syndrome were similar to other studies[9].

Table 10: Pack years of smoking and histology of lung cancer

\begin{tabular}{|l|c|c|c|}
\hline $\begin{array}{c}\text { Pack years of } \\
\text { smoking }\end{array}$ & adenocarcinoma & $\begin{array}{c}\text { Squamous cell } \\
\text { carcinoma }\end{array}$ & $\begin{array}{c}\text { Small cell } \\
\text { carcinoma }\end{array}$ \\
\hline 0 & 38 & 3 & 1 \\
\hline Less than 10 & 21 & 2 & 0 \\
\hline $10-20$ & 19 & 14 & 5 \\
\hline More than 20 & 1 & 3 & 1 \\
\hline
\end{tabular}

Table 11: Table showing superior vena cava obstruction (SVC) obstruction among study subjects with primary lung cancer in relation to histological type

\begin{tabular}{|l|c|c|c|}
\hline $\begin{array}{c}\text { SVC } \\
\text { obstruction }\end{array}$ & Adenocarcinoma & $\begin{array}{c}\text { Squamous cell } \\
\text { carcinoma }\end{array}$ & $\begin{array}{c}\text { Small cell } \\
\text { carcinoma }\end{array}$ \\
\hline Present & $5(6 \%)$ & $2(9 \%)$ & $4(57 \%)$ \\
\hline Absent & 74 & 20 & 3 \\
\hline Total & 79 & 22 & 7 \\
\hline
\end{tabular}

On chest X-ray most of our subjects had multiple findings (Table 11). Mass (86.20\%), collapse $(46 \%)$, pleural effusion $(38.7 \%)$ and consolidation in $11.2 \%$. these findings were similar to other studies[5,9]. There were a few variations in radiology of squamous cell cancer as compared to other histological variants. Cavitation was unique to squamous type however in other studies cavitaion was seen in adenocarcinoma also[9].

On chest CT, compared to our study other studies have shown higher radiological variations. Gupta et al., had reported more incidence of mediastinal adenopathy (79\% vs 31\%)[9]. However metastasis to contralateral lung was more in our study ( $20.6 \%$ vs $4.6 \%)$. These variations can be due to the lesser number of subjects with squamous and small cell histology where mediastinal adenopathy and local infiltration are more common.

Adenocarcinoma was the most common type of cancer among both males and females and also the most common among smokers and non-smokers. The higher incidence of adenocarcinoma may be due to non-active smoking causes like air pollution, second hand smoke exposure, and genetic factors. Squamous cell carcinoma showed a higher male preponderance and smoking history association. The number of pack years of smoking had a significant association with histology $(p=0.01)$. Majority of the persons with more than ten pack years of smoking had squamous type histology. (Table 10) This is in concordance with number of studies[5-7,9].

The most common presenting symptom in adenocarcinoma and squamous histology was cough,but hemoptysis was more common in squamous type. Also, in 12 patients of adenocarcinoma had consolidation like clinical features on presentation. Studies by Dinesh kumar et al., Gupta et al., also had shown that consolidation was commoner in adenocarcinoma than other histological types.[5,9] Among the clinical findings, clubbing and Pancost syndrome were commoner among squamous histology. Gupta et al., Kumar et al., Chhajed et al., had same results in their studies $[5,9,11]$.

SVC syndrome showed significant association with the histological type of lung cancer. (Table 11) Four out of seven patients $(57 \%)$ of small cell carcinoma had SVC syndrome. $(\mathrm{P}=0.001)$ This was similar to findings of Gupta et al.[9]. Blood vessel involvement, lymph node metastasis and brain metastasis were also more common with small cell histology.

The most common metastasis was malignant pleural effusion in 26(32.89\%) cases. Adenocarcinoma 
was the most common type of malignancy presenting as malignant pleural effusion. Also adenocarcinoma was the only histological type presenting with liver and adrenal metastasis. However in other studies, adrenal and liver metastasis were reported in squamous and small cell histological types also. This difference could be due to the comparatively lesser number of squamous cell lung cancer and small cell lung cancer types in our study. Small cell carcinoma patients had higher incidence of brain metastasis and lymph nodal metastasis. Among previous studies small cell brain metastasis showed similar higher numbers, but lymph nodal metastasis was less common[5,8,9].

The less common histological variants like carcinoids, inflammatory myofibroblastic tumor and adenocarcinoma presented with clinical and radiological features of lung collapse. All the five cases of carcinoid were endobronchial in location. Gupta et al., also has described endobronchial location as a common finding in carcinoid[9].

\section{Limitations}

Follow up and survival of patients could not be done in all the patients. Treatment modalities and response to treatment were not assessed.

\section{Conclusions}

Although lung cancer is a disease predominantly seen in elderly, it can occur even in teenage also. One of our study patients was nineteen years old. The incidence of lung cancer is increasing in non-smokers also. Adenocarcinoma is the most common histological variant. Even with the advances in diagnostic modalities still many patients present in advanced stages.

Conflicts of interest: None declared.

\section{Acknowledgements}

The authors would like to acknowledge the efforts of all the residents of the department of Pulmonary Medicine and Pathology. We also acknowledge the help rendered by Dr. R. Manju Associate Professor department of pulmonary medicine for the various bronchoscopy procedures.

\section{References}

1. Centers for Disease Control and Detection. Deaths: National Vital Statistics Reports, Final Data for 2012. NVSR 2014:63(9)1120.

2. Janerich DT, Thompson WD, Varela LR, et al. Lung cancer and exposure to tobacco smoke in the household. N Engl J Med 1990;323(10):632-36.

3. Bhatia R, Lopipero P, Smith AH. Diesel exhaust exposure \& lung cancer. Epidemiol 1998;9(1):84-91.

4. Driscoll T, Nelson DI, Steenand K, et al. The global burden of disease due to occupational carcinogens. Am J Ind Med 2005;48(6):419-31.

5. Sharma D K, Kumar M, Garg M, Jain P. Clinicopathological Profile of Lung Cancer - Changing Trends in India. Int J Res Med 2016;5(2);57-62.

6. Dhandapani S, Srinivasan A, Rajagopalan R, Chellamuthu S, Rajkumar A, Palaniswamy P. Clinicopathological Profile of Lung Cancer Patients in A Teaching Hospital in South India. J Cardiothorac Med 2016;4(2):440-43.

7. Malik PS, Sharma MC, Mohanti BK, Shukla NK, Deo SVS, Mohan A, Kumar G, Raina V. Clinico-pathological Profile of Lung Cancer at AIIMS: A Changing Paradigm in India. Asian Pacific J Cancer 2013;(1):489-94.

8. Agarwala A, Roy PP, Sarkar SK, Das SK, Banerjee A. Clinico-pathological profile of diagnosed patients of lung cancer with its relation to smoking habit and educational status in a medical college of paschim Medinipore west Bengal, India- A Tribal area prospective. Asian Pac J Health Sci 2014;1(4):479-85.

9. Gupta R, Chowdhary I, Singh P. Clinical, Radiological and Histological profile of Primary Lung Carcinomas. $J K$ Science 2015;17(3):146-51.

10. Gupta R C, Purohit S D, Sharma M P, Bhardwaj S. Primary bronchogenic carcinoma: Clinical profile of 279 cases from mid-west Rajasthan. Indian J Chest Dis Allied Sci 1998;40:109-16.

11. Chhajed PN, Athavale U, Shah A C. Clinical and pathological profile of 73 patients with lung carcinoma: Is the picture changing? JAPI 1999;47:483-87.

12. Thippanna G, Venu K, Gopalkrishnaiah V, Reddy PNS, Sai Charan BG. A profile of lung cancer patients in Hyderabad. J Indian Med Assoc 1999;97:357-59.

13. Goldstraw P, Crowley J, Chansky K, Giroux DJ, Groome PA, Rami-Porta R, Postmus PE, Rusch V, Sobin L, International Association for the Study of Lung Cancer International Staging Committee, Participating Institutions. The IASLC Lung Cancer Staging Project: proposals for the revision of the TNM stage groupings in the forthcoming (seventh) edition of the TNM Classification of malignant tumours. J Thorac Oncol 2007;2:706-14.

How to cite this article: Soman R, Govindaraj V, Saka V, Badhe B, Dubashi B. Clinico-pathological profile of primary lung cancer in a tertiary care center in South India. Indian J Immunol Respir Med. 2018;3(4):165-169. 